\title{
Effect of Mo-Doped Mesoporous Al-SSP Catalysts for the Catalytic Dehydration of Ethanol to Ethylene
}

\author{
Titinan Chanchuey, Chaowat Autthanit, and Bunjerd Jongsomjit \\ Center of Excellence on Catalysis and Catalytic Reaction Engineering, Department of Chemical Engineering, \\ Faculty of Engineering, Chulalongkorn University, Bangkok 10330, Thailand
}

Correspondence should be addressed to Bunjerd Jongsomjit; bunjerd.j@chula.ac.th

Received 14 September 2015; Revised 14 December 2015; Accepted 3 January 2016

Academic Editor: Juan M. Coronado

Copyright (C) 2016 Titinan Chanchuey et al. This is an open access article distributed under the Creative Commons Attribution License, which permits unrestricted use, distribution, and reproduction in any medium, provided the original work is properly cited.

\begin{abstract}
The catalytic dehydration of ethanol to ethylene over the mesoporous Al-SSP and Mo-doped Al-SSP catalysts was investigated. The Al-SSP catalyst was first synthesized by the modified sol-gel method and then doped with Mo by impregnation to obtain $1 \% \mathrm{Mo} / \mathrm{Al}-$ SSP and 5\% Mo/Al-SSP catalysts ( 1 and $5 \mathrm{wt} \%$ of Mo). The final catalysts were characterized using various techniques such as XRD, $\mathrm{N}_{2}$ physisorption, SEM/EDX, TEM, and $\mathrm{NH}_{3}-\mathrm{TPD}$. The catalytic activity for all catalysts in gas-phase ethanol dehydration reaction was determined at temperature range of $200^{\circ} \mathrm{C}$ to $400^{\circ} \mathrm{C}$. It was found that the most crucial factor influencing the catalytic activities appears to be the acidity. The acid property of catalysts depended on the amount of Mo loading. Increased Mo loading in Al-SSP resulted in increased weak acid sites, which enhanced the catalytic activity. Besides acidity, the high concentration of $\mathrm{Al}$ at surface of catalyst is also essential to obtain high activity. Based on the results, the most suitable catalyst in this study is $1 \% \mathrm{Mo} / \mathrm{Al}-\mathrm{SSP}$ catalyst, which can produce ethylene yield of ca. $90 \%$ at $300^{\circ} \mathrm{C}$ with slight amounts of diethyl ether (DEE) and acetaldehyde.
\end{abstract}

\section{Introduction}

Ethylene is an important feedstock for organic chemistry industry used in the preparation of polyethylene, ethylene oxide, vinyl chloride (from ethylene dichloride), and styrene (from ethyl benzene) [1]. Conventionally, it has been commercially produced by the thermal cracking of liquefied petroleum gas (LPG) or naphtha. According to the report by Kniel et al. [2], this method continues to dominate the industry today. True [3] reported the top ethylene producing complexes by capacity in tons per year, which are all steam cracking plants. In addition, Iles and Martin [4] reported the capacities of the Braskem and Solvay Indupa regarding ethanol to ethylene plants, while Voegle [5] reported the capacity of the Dow Chemical plant, which is currently under construction [3-5]. Compared to the conventional process, the catalytic dehydration of ethanol to ethylene is attractive because it requires lower temperature (less than $600^{\circ} \mathrm{C}$ ) [6] and it is cleaner technology. Moreover, ethanol can be produced from renewable sources including nonedible source such as molasses. At present, SynDol catalyst based on $\mathrm{MgO}$ $\mathrm{Al}_{2} \mathrm{O}_{3} / \mathrm{SiO}_{2}$ developed by Halcon $\mathrm{SD}$ has been employed commercially, achieving $99 \%$ of ethanol conversion and $95.83 \%$ of ethylene yield at $450^{\circ} \mathrm{C}$ [7]. Equate Petrochemical Company's plant (Kuwait) [3] achieved 99.7\% of ethylene selectivity and $100 \%$ of ethanol conversion using nanoscale HZSM-5 as the catalyst. It is known that the acid catalysts used in ethanol dehydration normally consist of silica and alumina-based catalysts. Upon the catalytic dehydration of ethanol, ethylene and diethyl ether (DEE) can be obtained using a solid acid catalyst as follows:

$$
\begin{aligned}
& \mathrm{C}_{2} \mathrm{H}_{5} \mathrm{OH} \longrightarrow \mathrm{C}_{2} \mathrm{H}_{4}+\mathrm{H}_{2} \mathrm{O} \\
& \mathrm{C}_{2} \mathrm{H}_{5} \mathrm{OH} \longrightarrow \mathrm{C}_{2} \mathrm{H}_{5} \mathrm{OC}_{2} \mathrm{H}_{5}+\mathrm{H}_{2} \mathrm{O} \\
& \mathrm{C}_{2} \mathrm{H}_{5} \mathrm{OH} \longrightarrow \mathrm{C}_{2} \mathrm{H}_{4} \mathrm{O}+\mathrm{H}_{2}
\end{aligned}
$$

The first reaction (1) has already been applied at the industrial level in the 1960s using aluminas as the catalysts [8]. The second reaction (2) occurs on the same catalysts under low temperature at moderate ethanol conversion, allowing very high selectivity and significant yields $(>70 \%)$. In addition, acetaldehyde can be obtained by dehydrogenation of ethanol as seen in the third reaction (3). There are many works in 
the literature related to the ethanol dehydration reaction over solid acid catalysts such as $\gamma$-alumina, zeolite, and silicaalumina $[9,10]$. There are also research articles directed at obtaining molybdenum oxide over solid acid catalysts in various reactions, which require acid site for active site such as $\mathrm{MoO}_{3} / \mathrm{Al}_{2} \mathrm{O}_{3}-\mathrm{SiO}_{2}$ in light olefin metathesis or partial oxidation $[11,12]$ and $\mathrm{MoO}_{3} / \mathrm{Al}_{2} \mathrm{O}_{3}$ in hydrodesulfurization of thiophene [13]. However, there are only a few works focused on molybdenum oxide for ethanol dehydration reaction. In continuation of our interest in using alumina and silica catalysts, the $\mathrm{SiO}_{2}$ is suitable as a support due to its high surface area, uniform pore size, excellent mechanical strength, and thermal stability such as hexagonal mesoporous silica, that is, spherical silica particle (SSP) [14]. Alumina is a good support due to its high metal dispersion ability and excellent mechanical properties. Moreover, the metal oxide promotes acidity in catalyst, and then this is interesting. The molybdenum oxide can enhance acidity in the catalyst. Thus, it is interesting to use molybdenum oxide with the silicaalumina acid catalysts.

In this study, the mesoporous SSP was synthesized and modified with alumina to obtain Al-SSP catalyst. Then, Mo was doped onto the Al-SSP catalysts. The relevant characterization techniques such as XRD, SEM, EDX, TEM, and $\mathrm{NH}_{3}$-TPD were carried out to reveal the physical and chemical properties of catalysts. The ethanol dehydration reaction of catalysts was performed to determine the catalytic activity and product selectivity.

\section{Materials and Methods}

2.1. Materials. The chemicals used for preparation of the catalysts were tetraethyl orthosilicate (TEOS) (98\%, Aldrich), cetyltrimethylammonium bromide (CTAB) (Aldrich), aluminium isopropoxide 98\% $\left[\mathrm{Al}\left(\mathrm{OP}^{\mathrm{i}}\right)_{3}\right]$ (Aldrich), ammonia 30\% (Panreac), isopropanol (Merck), and ammonium heptamolybdate-tetrahydrate (Merck). Gases employed were He (99.99\%, Air Liquide), $\mathrm{H}_{2}$ (99.999\%, Air Liquide), $\mathrm{N}_{2}$ (99.9999\%, Air Liquide), synthetic air (99.99\%, Air Liquide), and $\operatorname{Ar}$ (99.9\%, Air Liquide).

\subsection{Preparation of Catalysts}

2.2.1. Synthesis of Al-SSP. First, the spherical silica particle (SSP) was synthesized following the method described by Janlamool et al. [14] with the mixture of 1 TEOS : 0.3 CTAB : 11 $\mathrm{NH}_{3}: 58$ Ethanol:144 $\mathrm{H}_{2} \mathrm{O}$ (molar ratio). The resulting suspension was stirred at room temperature for $2 \mathrm{~h}$. After that, the white precipitate was separated from solvent by centrifuge. Then, the sample was dried at $110^{\circ} \mathrm{C}$ overnight and calcined in air at $550^{\circ} \mathrm{C}$ for $6 \mathrm{~h}$ to obtain the SSP support. In order to prepare Al-SSP, the SSP was added into the solution of aluminium isopropoxide in isopropanol (to obtain $60 \mathrm{wt} \%$ of $\mathrm{Al}$ ). The mixture was stirred for $1 \mathrm{~h}$ at room temperature. Then, it was added into ammonia solution for hydrolysis. Then, the mixture was stirred at room temperature for $20 \mathrm{~h}$. The Al-SSP catalyst was dried at $110^{\circ} \mathrm{C}$ for $24 \mathrm{~h}$. The dried sample was calcined in air at $650^{\circ} \mathrm{C}$ for $2 \mathrm{~h}$ [15]. The surface area of Al-SSP catalyst obtained was $443 \mathrm{~m}^{2} / \mathrm{g}$ using $\mathrm{N}_{2}$ physisorption technique.

2.2.2. Synthesis of Mo/Al-SSP. Mo/Al-SSP catalysts were prepared by impregnation of Mo precursor onto the Al-SSP obtained above. First, the desired amount of ammonium heptamolybdate-tetrahydrate was dissolved in DI water. Secondly, this solution was added into the Al-SSP. The Mo/AlSSP catalyst was dried at $110^{\circ} \mathrm{C}$ for $4 \mathrm{~h}$ and calcined in air at $550^{\circ} \mathrm{C}$ for $4 \mathrm{~h}$. The Mo-doped Al-SSP catalyst was denoted as $X$ Mo/Al-SSP, where $X$ ( 1 and $5 \mathrm{wt} \%)$ indicates the wt $\%$ of molybdenum.

2.3. Characterization of Catalysts. The bulk phase of catalyst was determined by SIEMENS D500 X-ray diffractometer (XRD), using $\mathrm{CuK}_{\alpha}$ radiation with $\mathrm{Ni}$ filter in the $2 \theta$ range of 10-90 degrees having the resolution of $0.02^{\circ}$.

The surface area and average pore volume of prepared catalysts were determined by $\mathrm{N}_{2}$-physisorption using Micromeritics ChemiSorb 2750 Pulse instrument. Measurement was performed at $-196^{\circ} \mathrm{C}$ and calculated according to the Brunauer, Emmet, and Teller (BET) isotherm equation.

The morphology and elemental distribution over the catalysts surface were determined by scanning electron microscope (SEM) and energy X-ray spectroscopy (EDX). The SEM model was JEOL mode JSM-5800LV and Link Isis series 300 program was performed for EDX.

The molybdenum particle dispersion of all catalysts was observed by using JEOL-JEM 200CX transmission electron microscope (TEM) operated at $200 \mathrm{kV}$.

The acidity of catalysts was estimated by temperatureprogrammed desorption of ammonia ( $\mathrm{NH}_{3}$-TPD) using Micromeritics Chemisorb 2750 pulse chemisorption system. The catalyst sample was pretreated at $400^{\circ} \mathrm{C}$ in a flow of helium. The sample was saturated with $15 \% \mathrm{NH}_{3} / \mathrm{He}$ at $120^{\circ} \mathrm{C}$ for $1 \mathrm{~h}$. After saturation, the physisorbed ammonia was desorbed in a helium gas flow. Then, the sample was heated from 40 to $800^{\circ} \mathrm{C}$ at a heating rate of $10^{\circ} \mathrm{C} / \mathrm{min}$. The amount of ammonia in effluent was measured via the thermal conductivity detector (TCD) as a function of temperature [16].

2.4. Ethanol Dehydration Reaction. Activity and product distribution via gas-phase ethanol dehydration reaction of catalysts were determined using a fixed-bed microreactor (I.D. $=7 \mathrm{~mm}$ and length $=0.33 \mathrm{~m}$, made from a borosilicate glass tube). A glass reactor was placed into a temperatureprogrammed tubular furnace. All experiments were performed under atmospheric pressure and in the temperature range of 200 to $400^{\circ} \mathrm{C}$ using a feed composition consisting of $99.95 \%$ of ethanol. In this experiment, about $0.05 \mathrm{~g}$ of catalyst obtained from Sections 2.2.1 and 2.2.2 was charged into the middle zone of reactor tube and pure ethanol as feed was stored in vaporizer. Prior to testing, the catalyst was activated at $200^{\circ} \mathrm{C}$ for $1 \mathrm{~h}$ under argon. Ethanol was conveyed into reactor by argon gas flow rate of $50 \mathrm{~mL} / \mathrm{min}$. The reaction was carried out at each temperature for $1 \mathrm{~h}$ [17]. The reaction products were analyzed by gas chromatography using the 
TABLE 1: Textural properties of the catalysts.

\begin{tabular}{lccc}
\hline Catalysts & $\begin{array}{c}\text { Surface area } \\
\left(\mathrm{m}^{2} / \mathrm{g}\right)\end{array}$ & $\begin{array}{c}\text { Average pore } \\
\text { diameter } \\
(\mathrm{nm})\end{array}$ & $\begin{array}{c}\text { Average pore } \\
\text { volume }\left(\mathrm{cm}^{3} / \mathrm{g}\right)\end{array}$ \\
\hline Al-SSP & 443.6 & 5.9 & 0.81 \\
$1 \% \mathrm{Mo} / \mathrm{Al}-\mathrm{SSP}$ & 357.7 & 7.2 & 0.59 \\
$5 \% \mathrm{Mo} / \mathrm{Al}-\mathrm{SSP}$ & 492.4 & 3.9 & 0.58 \\
\hline
\end{tabular}

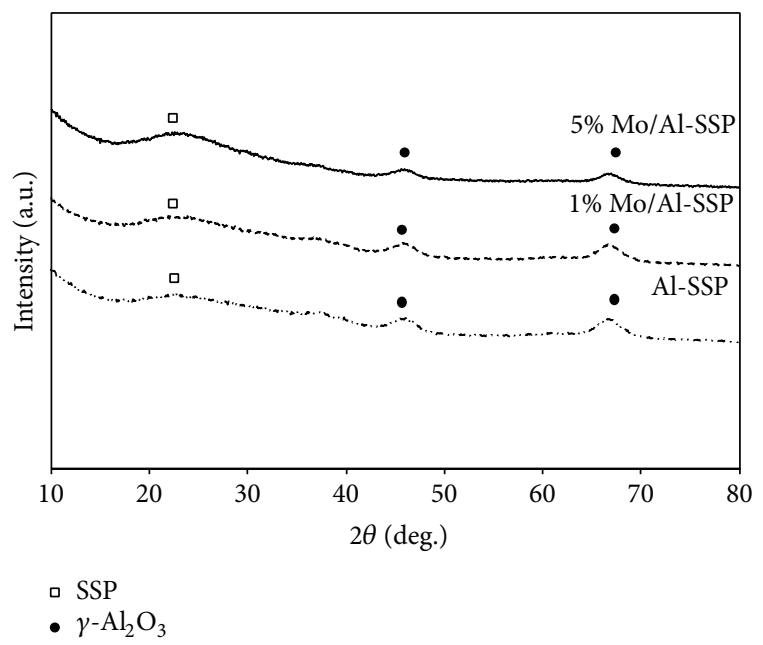

FIGURE 1: XRD patterns of all catalysts.

flame ionization detector (FID), Shimadzu GC14B equipping with DB-5 capillary column.

\section{Results and Discussion}

3.1. Characteristics of Catalyst. The Al-SSP, $1 \% \mathrm{Mo} / \mathrm{Al}-\mathrm{SSP}$, and $5 \% \mathrm{Mo} / \mathrm{Al}-\mathrm{SSP}$ catalysts were characterized using various techniques. To identify the crystalline structure of the catalysts after Mo doping, the X-ray diffraction was performed. As shown in Figure 1, it can be observed that the Al-SSP catalyst exhibited the XRD peaks at $21-24^{\circ}$ (broad) indicating the presence of amorphous structure of silica. Besides, the more sharp peaks around 45 and $67^{\circ}$ were also observed for this sample indicating the presence of $\gamma-\mathrm{Al}_{2} \mathrm{O}_{3}$ crystallite [18]. However, after doping 1 and $5 \mathrm{wt} \%$ of Mo in Al-SSP, both Mo-doped Al-SSP catalysts still exhibited the similar XRD patterns as seen for those of Al-SSP. This revealed that the crystalline structure of the catalysts did not change with Mo doping. In addition, the Mo species cannot be detected because they are present in the highly dispersed form (the crystallite size is less than $3 \mathrm{~nm}$ ).

The textural properties and nitrogen adsorption/ desorption isotherms of the catalysts are summarized in Table 1 and Figure 2. According to the IUPAC classification, both support and catalysts exhibit Type IV isotherms, which are typical of mesoporous materials. For Al-SSP and 1\% $\mathrm{Mo} / \mathrm{Al}-\mathrm{SSP}$, the sample presented hysteresis loop of Type $\mathrm{H} 1$, occurring at higher relative pressure $\left(P / P_{0}=0.7\right.$ to $0.9)$ compared to $5 \% \mathrm{Mo} / \mathrm{Al}-\mathrm{SSP}$ catalyst. It indicates larger mesopores and broad pore size distribution with cylindrical

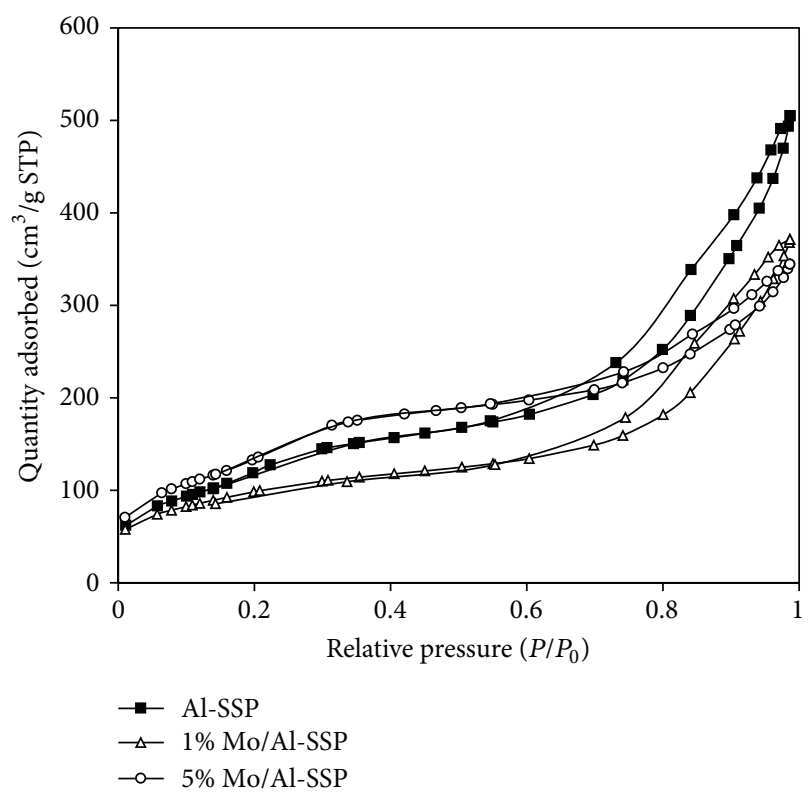

FIGURE 2: Nitrogen adsorption/desorption isotherms of all catalysts.

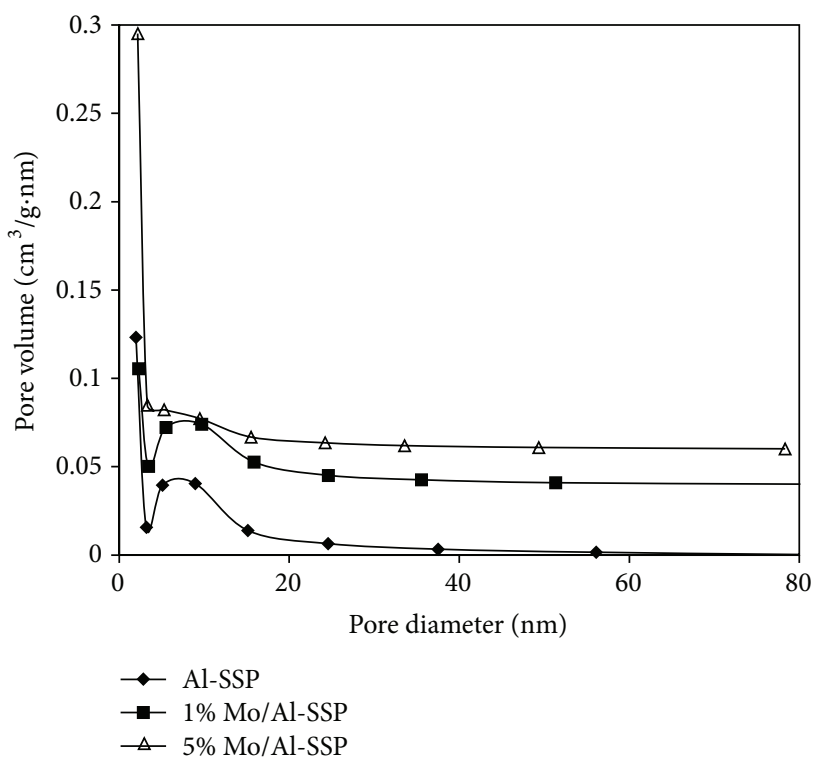

FIgURE 3: BJH pore size distribution of all catalysts.

shapes. The observation is consistent with the value of surface area and sample porosity as shown in Table 1 , in which the pore volume of Al-SSP, $1 \% \mathrm{Mo} / \mathrm{Al}-\mathrm{SSP}$, and $5 \%$ Mo/Al-SSP was $0.81,0.59$, and $0.58 \mathrm{~cm}^{3} / \mathrm{g}$, respectively. The incorporation of molybdenum into Al-SSP decreases the surface area, mainly due to the blockage of pore. Moreover, the pores of this catalyst were blocked, suggesting that the Mo at higher loading ( $>1 \mathrm{wt} \%)$ was not well dispersed in the supports. However, the surface area of $5 \mathrm{wt} \%$ Mo did not follow this trend. This may be because the Mo was located on the external surfaces indicating that Mo was not incorporated into the channels of Al-SSP leading to an increase in surface area. The pore size distribution (PSD) calculated by $\mathrm{BJH}$ method is shown in Figure 3. For all catalysts, the samples 

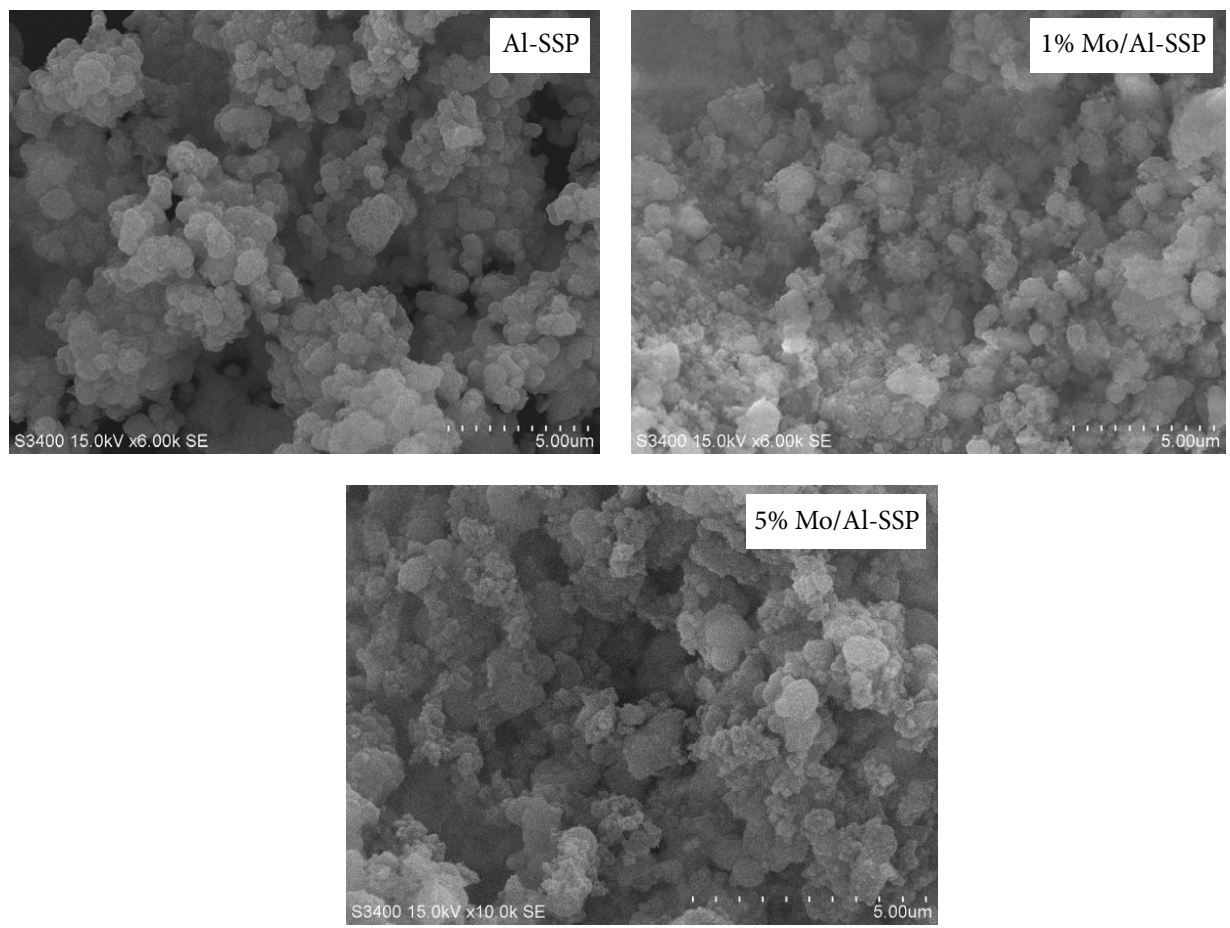

FIGURE 4: The SEM micrographs of all catalysts.
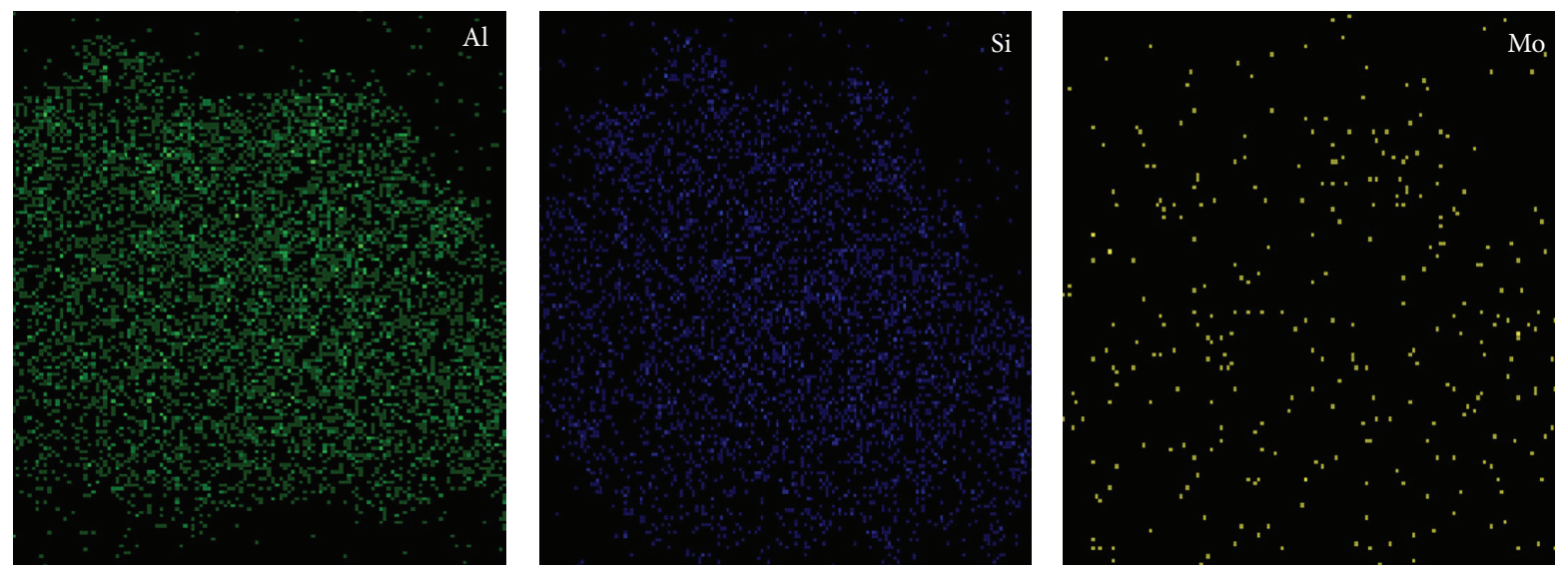

FIgURE 5: The typical EDX mapping of $1 \% \mathrm{Mo} / \mathrm{Al}-\mathrm{SSP}$ catalyst.

have a narrow pore size distribution with an average pore diameter around 3.9-7.2 nm, confirming that the pore size distribution is in the mesoporous range. It can be seen that the calculated pore size distribution was in good agreement with $\mathrm{N}_{2}$ isotherm as mentioned above.

The morphology of the catalysts was determined using SEM as shown in Figure 4. The morphology of the Al-SSP catalyst was apparently spheroidal with agglomeration of particles having the average particle size around 0.5 microns. After doping the Al-SSP with Mo, it can be seen that there was no significant change in the morphology of catalysts.
The dispersive X-ray spectroscopy (EDX) was also performed to determine the elemental distribution in the catalyst granule. All elements such as $\mathrm{Al}, \mathrm{Si}, \mathrm{O}$, and Mo can be detected using the EDX mapping mode. Hence, the location of the specified element can be illustrated by the dots. The dense of dots is related to the amount of element present. The typical EDX mapping of $1 \%$ Mo/Al-SSP catalyst is shown in Figure 5. In this figure, the distribution of $\mathrm{Al}, \mathrm{Si}$, and $\mathrm{Mo}$ was observed. The density of $\mathrm{Al}$ and $\mathrm{Si}$ was strongly observed because $\mathrm{Al}$ and $\mathrm{Si}$ are the main components of Al-SSP catalyst. After Mo doping, the well distribution of Mo was evident. This result 


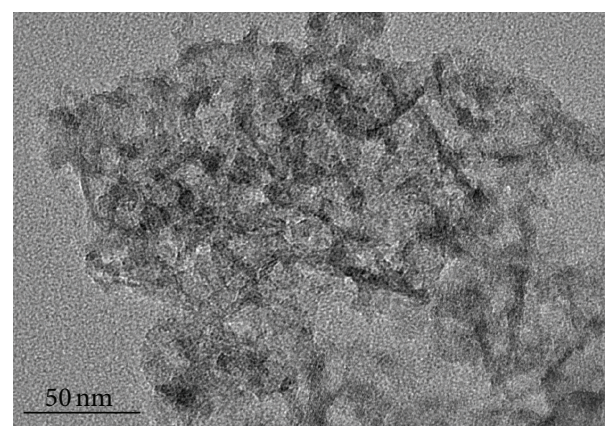

FIGURE 6: The typical TEM image of 1\% Mo/Al-SSP catalyst.

TABLE 2: The amount of each element near the surface of catalyst granule obtained from EDX.

\begin{tabular}{lcccc}
\hline \multirow{2}{*}{ Catalysts } & \multicolumn{4}{c}{ Amount of weight on surface (wt\%) } \\
& $\mathrm{Al}$ & $\mathrm{Si}$ & $\mathrm{O}$ & $\mathrm{Mo}$ \\
\hline Al-SSP & 40.6 & 7.5 & 51.9 & 0 \\
$1 \% \mathrm{Mo} / \mathrm{Al}-\mathrm{SSP}$ & 27.2 & 18.5 & 49.9 & 4.4 \\
$5 \% \mathrm{Mo} / \mathrm{Al}-\mathrm{SSP}$ & 13.4 & 29.3 & 49.5 & 7.8 \\
\hline
\end{tabular}

is in accordance with that obtained from XRD, where the Mo species are present in the highly dispersed form, which cannot be detected by the XRD measurement.

Besides the EDX mapping, the amount of each element near the surface of catalyst granule can be determined quantitatively. The results are summarized in Table 2. The key elements to be considered are $\mathrm{Al}$ and $\mathrm{Mo}$. It can be seen that mostly $\mathrm{Al}$ species $(\mathrm{Al}=27.2 \%)$ in $1 \% \mathrm{Mo} / \mathrm{Al}-\mathrm{SSP}$ catalyst were located at the catalyst surface compared to that in 5\% $\mathrm{Mo} / \mathrm{Al}$-SSP catalyst $(\mathrm{Al}=13.4 \%)$. For both Mo-doped Al-SSP catalysts, Mo species were also located at the catalyst surface since the amounts of Mo obtained from EDX were larger than those of Mo loading. The location of $\mathrm{Al}$ species could play an important role on the catalytic activity as well.

In order to investigate the dispersion of Mo species, the transmission electron microscope (TEM) image was obtained as shown in Figure 6. It is known that gamma alumina is present as wrinkled sheets located throughout the SSP. As seen from the figure, the dark patches represent the Mo species being dispersed in the alumina wrinkled sheets. It was found that the dispersion of Mo species observed from TEM was corresponding to the very small crystallite size (less than $3 \mathrm{~nm}$ ) of Mo species obtained from the XRD measurement as mentioned above.

The acid properties of catalysts are crucial to determine the catalytic activity and product distribution via ethanol dehydration reaction. Hence, the $\mathrm{NH}_{3}$ temperatureprogrammed desorption $\left(\mathrm{NH}_{3}\right.$-TPD) was performed. Table 3 shows the surface acidity of all catalysts in this study. The assignment of desorption peaks between 175 and $300^{\circ} \mathrm{C}$ is weak acid sites and the desorption peaks occurring above $300^{\circ} \mathrm{C}$ refer to medium-strong acid sites [19]. It indicates that the Al-SSP catalyst exhibits the lowest amount of weak acid

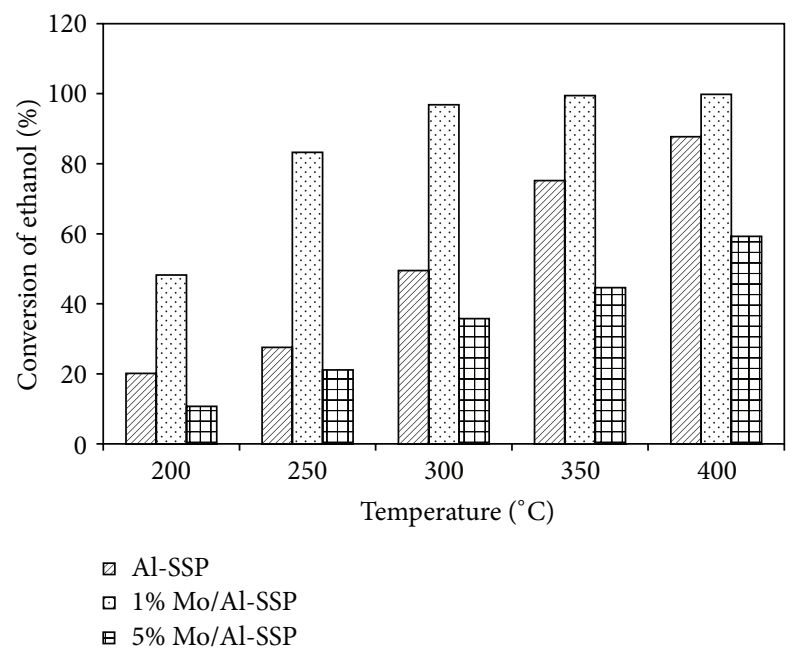

Figure 7: Ethanol conversion at different temperatures of all catalysts.

TABLE 3: The surface acidity of all catalysts from $\mathrm{NH}_{3}$-TPD.

\begin{tabular}{lccc}
\hline \multirow{2}{*}{ Catalysts } & \multicolumn{3}{c}{ Number of acid sites (mmole/g. cat) } \\
Weak acid sites & $\begin{array}{c}\text { Medium-strong } \\
\text { acid sites }\end{array}$ & Total acid site \\
\hline Al-SSP & 0.25 & 1.45 & 1.70 \\
$1 \% \mathrm{Mo} / \mathrm{Al}-\mathrm{SSP}$ & 0.33 & 1.37 & 1.70 \\
$5 \% \mathrm{Mo} / \mathrm{Al}-\mathrm{SSP}$ & 0.78 & 1.11 & 1.99 \\
\hline
\end{tabular}

site, whereas the $5 \% \mathrm{Mo} / \mathrm{Al}-\mathrm{SSP}$ contains the largest weak and total acid sites. It can be observed that the Mo doping can alter the acidity of Al-SSP catalyst. Adding more amount of Mo apparently resulted in increased significant amount of weak acid site as seen in Table 3. It should be noted that the amount of weak acid site is probably more related to the Brønsted acid site, whereas Lewis acid site is more related to the amount of strong acid site [20]. In ethanol dehydration reaction, the Brønsted acid site is preferred.

3.2. Ethanol Dehydration Reaction. In order to measure the catalytic activity and product distribution, ethanol dehydration reaction was performed over all catalysts at atmospheric pressure with temperature ranging from 200 to $400^{\circ} \mathrm{C}$. The results of ethanol conversion for all catalysts are shown in Figure 7. For all catalysts, increased temperature apparently resulted in an increase in ethanol conversion. However, among all catalysts, the $1 \% \mathrm{Mo} / \mathrm{Al}-\mathrm{SSP}$ exhibits the highest conversion (ca. $100 \%$ conversion at $350^{\circ} \mathrm{C}$ ). It can be observed that the ethanol conversion obtained from 5\% Mo/Al-SSP catalyst is the lowest, although this catalyst has the highest amount of weak and total acid sites (Table 3). It should be noted that the amount of $\mathrm{Al}$ at catalyst surface for this sample is the lowest based on the EDX result (Table 2). Hence, this is probably the main reason for the $5 \% \mathrm{Mo} / \mathrm{Al}-\mathrm{SSP}$ catalyst to yield the lowest conversion. 
TABLE 4: Product yield obtained from ethanol dehydration at $300^{\circ} \mathrm{C}$.

\begin{tabular}{lccc}
\hline \multirow{2}{*}{ Catalysts } & \multicolumn{3}{c}{ Yield of products (wt\%) } \\
& Ethylene & Diethyl ether & Acetaldehyde \\
\hline Al-SSP & 49.07 & 0.00 & 0.44 \\
$1 \% \mathrm{Mo} / \mathrm{Al}-\mathrm{SSP}$ & 90.11 & 0.68 & 6.06 \\
$5 \% \mathrm{Mo} / \mathrm{Al}-\mathrm{SSP}$ & 29.25 & 1.09 & 5.45 \\
\hline
\end{tabular}

Considering the product distribution, the selectivity of ethylene is related to the reaction temperature as also reported by Zhang et al. [21]. Ethylene selectivity is shown in Figure 8. For Al-SSP catalyst, ethylene selectivity was the highest even at low temperature, while it gradually increased for the Mo-doped Al-SSP catalysts with increased temperature. It is suggested that the Mo doping could result in decreased ethylene selectivity, especially at lower temperature. However, the effect of Mo doping is less pronounced at higher temperature.

It should be noted that, during ethanol dehydration, byproducts such as diethyl ether (DEE) and acetaldehyde were also obtained. The selectivity of byproduct is shown in Figure 9. At lower temperature (ca. 200 to $300^{\circ} \mathrm{C}$ ), DEE was significantly produced via dehydration of ethanol. At temperature above $350^{\circ} \mathrm{C}$, there was no DEE obtained due to its decomposition to ethylene at high temperature. Acetaldehyde is also produced by dehydrogenation of ethanol as a side reaction. As seen from the figure, increased temperature resulted in a slight decrease in selectivity of acetaldehyde, which was also reported by Nair et al. [22].

In order to compare the catalyst performance, the ethylene yield (product of conversion and selectivity) along with other byproducts obtained from ethanol dehydration at $300^{\circ} \mathrm{C}$ is calculated as shown in Table 4 . It was found that the $1 \% \mathrm{Mo} / \mathrm{Al}-\mathrm{SSP}$ catalyst rendered the highest ethylene yield with slight amounts of DEE and acetaldehyde. This is attributed to increased weak acid sites and large amount of $\mathrm{Al}$ present at the catalyst surface with $1 \mathrm{wt} \%$ of Mo doping onto Al-SSP catalyst.

Table 5 shows a comparison of the catalytic ability for ethanol dehydration to ethylene over various catalysts reported so far. It was obvious that $1 \% \mathrm{Mo} / \mathrm{Al}-\mathrm{SSP}$ is competitive among other typical and modified catalysts. Finally, it should be emphasized that, apart from their interesting intrinsic activity, the Mo/Al-SSP tested in this study was highly stable, thus making them have potential for industrial applications.

\section{Summary}

Ethanol dehydration reaction from the temperature range of 200 to $400^{\circ} \mathrm{C}$ over Al-SSP, $1 \% \mathrm{Mo} / \mathrm{Al}-\mathrm{SSP}$, and $5 \% \mathrm{Mo} / \mathrm{Al}-$ SSP catalysts was investigated. It appears that the $1 \% \mathrm{Mo} / \mathrm{Al}-$ SSP catalyst exhibited the highest ethanol conversion and ethylene yield of ca. $90 \%$ (at $300^{\circ} \mathrm{C}$ ). This can be attributed to the increased acidity and proper amount of $\mathrm{Al}$ at catalyst surface with Mo doping. However, too large amount of Mo

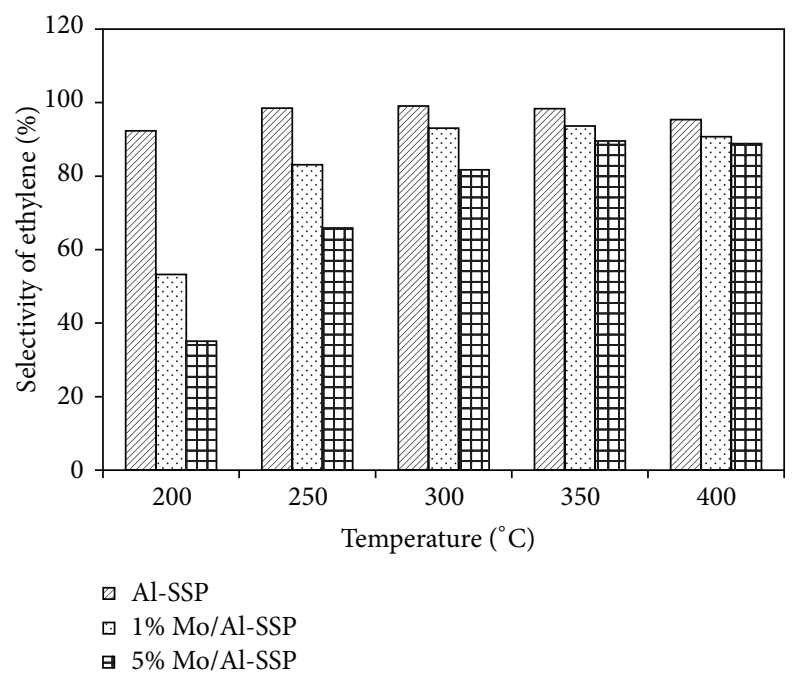

FIGURE 8: Ethylene selectivity at different temperatures of all catalysts.

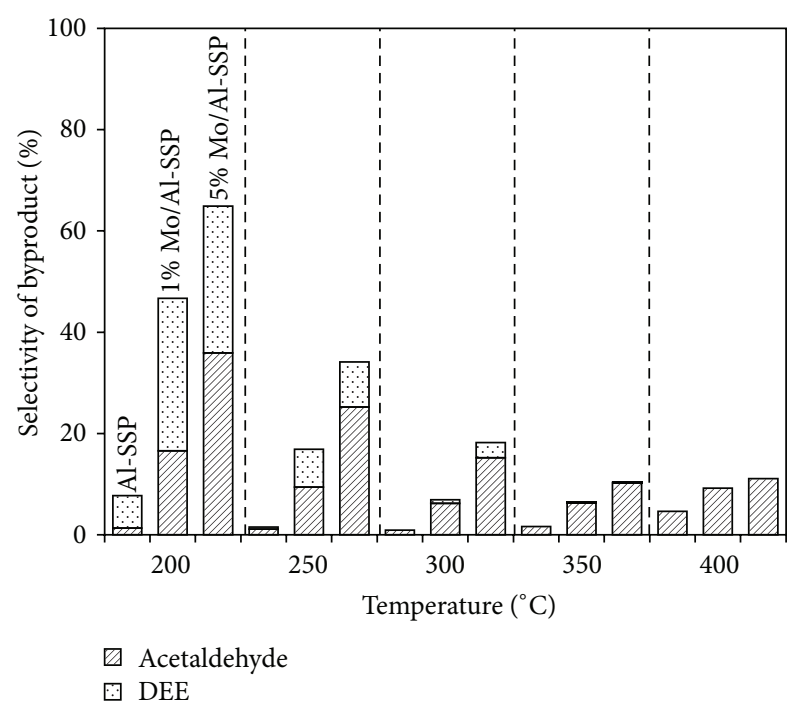

FIGURE 9: The selectivity of byproducts at different temperatures of all catalysts.

doping (i.e., $5 \mathrm{wt} \%$ ) apparently resulted in decreased amount of $\mathrm{Al}$ at catalyst surface leading to low ethanol conversion.

\section{Conflict of Interests}

The authors declare that there is no conflict of interests regarding the publication of this paper.

\section{Acknowledgments}

The authors thank the Thailand Research Fund (BRG5780009 and IRG5780014), National Research University Project, Ratchadaphiseksomphot Endowment Fund (2015) of Chulalongkorn University (CU-58-027-AM), and the National 
TABLE 5: A comparison of catalysts for ethylene synthesis and their catalytic ability.

\begin{tabular}{|c|c|c|c|c|c|c|}
\hline Catalysts & $\begin{array}{l}\text { Surface area } \\
\qquad\left(\mathrm{m}^{2} / \mathrm{g}\right)\end{array}$ & $\begin{array}{c}\text { Amount of } \\
\text { catalyst }\end{array}$ & $\begin{array}{c}\text { Reaction } \\
\text { temperature } \\
\left({ }^{\circ} \mathrm{C}\right) \\
\end{array}$ & $\begin{array}{c}\text { Space } \\
\text { velocity }\left(\mathrm{h}^{-1}\right)\end{array}$ & $\begin{array}{c}\text { Ethylene yield } \\
(\mathrm{wt} \%)\end{array}$ & Ref. \\
\hline $1 \% \mathrm{Mo} / \mathrm{Al}-\mathrm{SSP}$ & 357.7 & $0.05 \mathrm{~g}$ & 300 & WHSV 8.4 & 90.11 & This work \\
\hline Al-SV & 215 & $0.05 \mathrm{~g}$ & $250-300$ & WHSV 8.4 & $53-100$ & [17] \\
\hline $\mathrm{MoO}_{2}$ & 6 & $0.15 \mathrm{~g}$ & 300 & ${ }^{*}$ n.a. & 19.4 & {$[23,24]$} \\
\hline $0.5 \%$ La-2\% P-HZSM-5 & 194 & $0.50 \mathrm{~g}$ & $200-300$ & WHSV 2.0 & $10.2-99.9$ & {$[25]$} \\
\hline $\mathrm{TiO}_{2} / \gamma-\mathrm{Al}_{2} \mathrm{O}_{3}$ & 187 & $1.15 \mathrm{~mL}$ & $360-550$ & LHSV 26-104 & 91.99 & {$[26]$} \\
\hline Commercial $\mathrm{Al}_{2} \mathrm{O}_{3}$ & 190 & $3.0 \mathrm{~mL}$ & 450 & LHSV 3.0 & 78.1 & [21] \\
\hline
\end{tabular}

${ }^{*}$ n.a. $=$ not applicable.

Research Council of Thailand (NRCT) for the financial support of this project.

\section{References}

[1] D. Fan, D.-J. Dai, and H.-S. Wu, "Ethylene formation by catalytic dehydration of ethanol with industrial considerations," Materials, vol. 6, no. 1, pp. 101-115, 2013.

[2] L. Kniel, O. Winter, and K. Stork, Ethylene, Keystone to the Petrochemical Industry, M. Dekker, New York, NY, USA, 1980.

[3] W. R. True, "Global ethylene capacity continues to advance in 2011," December 2015, http://www.ogj.com/articles/print/ vol-110/issue-07/special-report-ethylene-report/global-ethylenecapacity.html.

[4] A. Iles and A. N. Martin, "Expanding bioplastics production: sustainable business innovation in the chemical industry," Journal of Cleaner Production, vol. 45, pp. 38-49, 2013.

[5] E. Voegle, "Feeding the chemical market," Ethanol Producer Magazine, 2012, http://www.ethanolproducer.com/articles/ 8617/feeding-the-chemical-market.

[6] T. K. Phung, L. Proietti Hernández, and G. Busca, "Conversion of ethanol over transition metal oxide catalysts: effect of tungsta addition on catalytic behaviour of titania and zirconia," Applied Catalysis A: General, vol. 489, pp. 180-187, 2014.

[7] N. K. Kochar, R. Merims, and A. S. Padia, "Ethylene from ethanol," Chemical Engineering Progress, vol. 77, no. 6, pp. 6670, 1981 .

[8] P. Imhof and J. C. van der Waal, Catalytic Process Development for Renewable Materials, Wiley-VCH, Weinheim, Germany, 2013.

[9] I. Takahara, M. Saito, M. Inaba, and K. Murata, "Dehydration of ethanol into ethylene over solid acid catalysts," Catalysis Letters, vol. 105, no. 3-4, pp. 249-252, 2005.

[10] J. Bedia, R. Barrionuevo, J. Rodríguez-Mirasol, and T. Cordero, "Ethanol dehydration to ethylene on acid carbon catalysts," Applied Catalysis B: Environmental, vol. 103, no. 3-4, pp. 302310, 2011.

[11] D. P. Debecker, B. Schimmoeller, M. Stoyanova et al., "Flamemade $\mathrm{MoO}_{3} / \mathrm{SiO}_{2}-\mathrm{Al}_{2} \mathrm{O}_{3}$ metathesis catalysts with highly dispersed and highly active molybdate species," Journal of Catalysis, vol. 277, no. 2, pp. 154-163, 2011.

[12] D. P. Debecker, D. Hauwaert, M. Stoyanova, A. Barkschat, U. Rodemerck, and E. M. Gaigneaux, "Opposite effect of $\mathrm{Al}$ on the performances of $\mathrm{MoO}_{3} / \mathrm{SiO}_{2}-\mathrm{Al}_{2} \mathrm{O}_{3}$ catalysts in the metathesis and in the partial oxidation of propene," Applied Catalysis A: General, vol. 391, no. 1-2, pp. 78-85, 2011.

[13] T. Kitano, S. Okazaki, T. Shishido, K. Teramura, and T. Tanaka, "Brønsted acid generation of alumina-supported molybdenum oxide calcined at high temperatures: characterization by acidcatalyzed reactions and spectroscopic methods," Journal of Molecular Catalysis A: Chemical, vol. 371, pp. 21-28, 2013.

[14] J. Janlamool, P. Praserthdam, and B. Jongsomjit, "Ti-Si composite oxide-supported cobalt catalysts for $\mathrm{CO}_{2}$ hydrogenation," Journal of Natural Gas Chemistry, vol. 20, no. 5, pp. 558-564, 2011.

[15] W. Phongsawat, B. Netiworaruksa, K. Suriye, S. Dokjampa, P. Praserthdam, and J. Panpranot, "Role of support nature $(\gamma$ $\mathrm{Al}_{2} \mathrm{O}_{3}$ and $\mathrm{SiO}_{2}-\mathrm{Al}_{2} \mathrm{O}_{3}$ ) on the performances of rhenium oxide catalysts in the metathesis of ethylene and 2-pentene," Journal of Natural Gas Chemistry, vol. 21, no. 2, pp. 158-164, 2012.

[16] Z. Li, F. Meng, J. Ren, H. Zheng, and K. Xie, "Surface structure and catalytic performance of $\mathrm{CuCl} / \mathrm{SiO}_{2}-\mathrm{Al}_{2} \mathrm{O}_{3}$ catalysts for methanol oxidative carbonylation," Chinese Journal of Catalysis, vol. 29, no. 7, pp. 643-648, 2008.

[17] M. Wannaborworn, P. Praserthdam, and B. Jongsomjit, "A comparative study of solvothermal and sol-gel-derived nanocrystalline alumina catalysts for ethanol dehydration," Journal of Nanomaterials, vol. 2015, Article ID 519425, 11 pages, 2015.

[18] F. F. Madeira, N. S. Gnep, P. Magnoux, S. Maury, and N. Cadran, "Ethanol transformation over HFAU, HBEA and HMFI zeolites presenting similar Brønsted acidity," Applied Catalysis A: General, vol. 367, no. 1-2, pp. 39-46, 2009.

[19] J. Handzlik, J. Ogonowski, J. Stoch, M. Mikołajczyk, and P. Michorczyk, "Properties and metathesis activity of molybdenaalumina, molybdena-silica-alumina and molybdena-silica catalysts-a comparative study," Applied Catalysis A: General, vol. 312, no. 1-2, pp. 213-219, 2006.

[20] J. A. Cecilia, C. García-Sancho, J. M. Mérida-Robles, J. Santamaría-González, R. Moreno-Tost, and P. Maireles-Torres, "V and V-P containing Zr-SBA-15 catalysts for dehydration of glycerol to acrolein," Catalysis Today, vol. 254, pp. 43-52, 2015.

[21] X. Zhang, R. Wang, X. Yang, and F. Zhang, "Comparison of four catalysts in the catalytic dehydration of ethanol to ethylene," Microporous and Mesoporous Materials, vol. 116, no. 1-3, pp. 210-215, 2008.

[22] H. Nair, J. E. Gatt, J. T. Miller, and C. D. Baertsch, "Mechanistic insights into the formation of acetaldehyde and diethyl ether from ethanol over supported $\mathrm{VO}_{x}, \mathrm{MoO}_{x}$, and $\mathrm{WO}_{x}$ catalysts," Journal of Catalysis, vol. 279, no. 1, pp. 144-154, 2011. 
[23] Y. Nakamura, T. Murayama, and W. Ueda, "Reduced vanadium and molybdenum oxides catalyze the equivalent formation of ethane and acetaldehyde from ethanol," ChemCatChem, vol. 6, no. 3, pp. 741-744, 2014.

[24] Y. Nakamura, T. Murayama, and W. Ueda, "Hydrogen-transfer dehydration between alcohols over $\mathrm{V}_{2} \mathrm{O}_{3}$ and $\mathrm{MoO}_{2}$ catalysts for the formation of corresponding alkanes and aldehydes," Journal of Molecular Catalysis A: Chemical, vol. 394, pp. 137-144, 2014.

[25] N. Zhan, Y. Hu, H. Li, D. Yu, Y. Han, and H. Huang, "Lanthanum-phosphorous modified HZSM-5 catalysts in dehydration of ethanol to ethylene: a comparative analysis," Catalysis Communications, vol. 11, no. 7, pp. 633-637, 2010.

[26] G. Chen, S. Li, F. Jiao, and Q. Yuan, "Catalytic dehydration of bioethanol to ethylene over $\mathrm{TiO}_{2} / \gamma-\mathrm{Al}_{2} \mathrm{O}_{3}$ catalysts in microchannel reactors," Catalysis Today, vol. 125, no. 1-2, pp. 111119, 2007. 

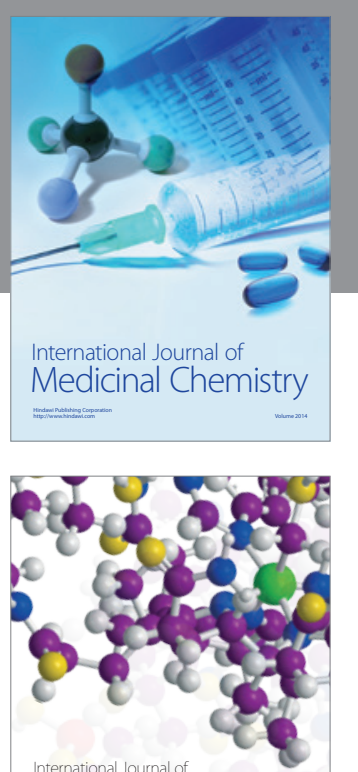

Carbohydrate Chemistry

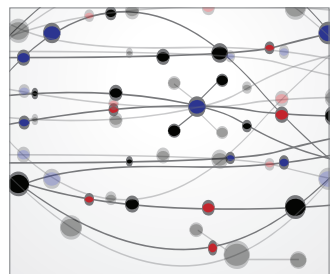

The Scientific World Journal
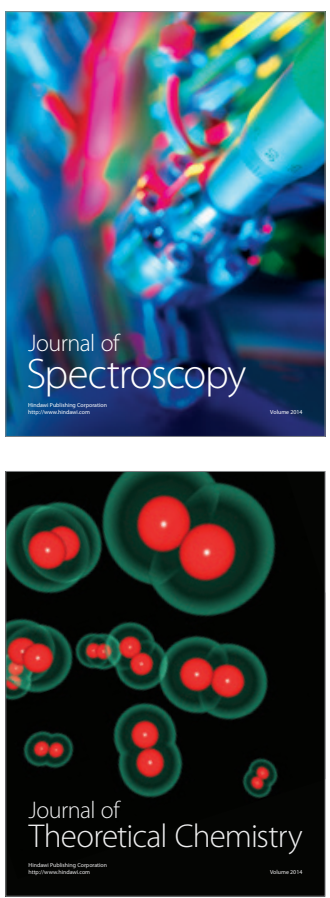
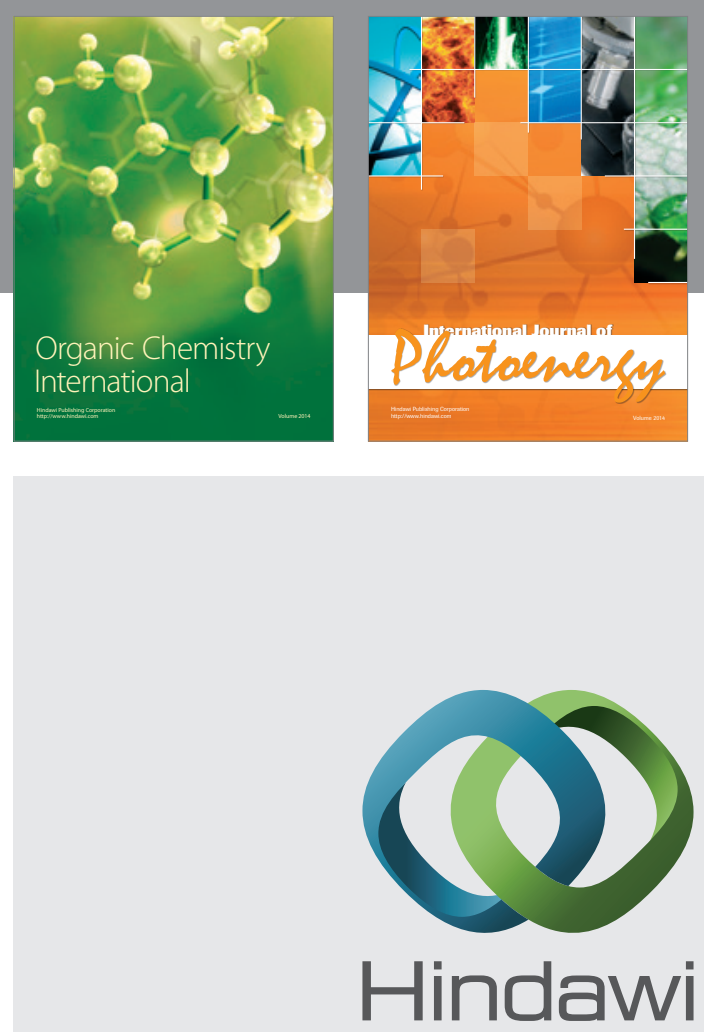

Submit your manuscripts at

http://www.hindawi.com

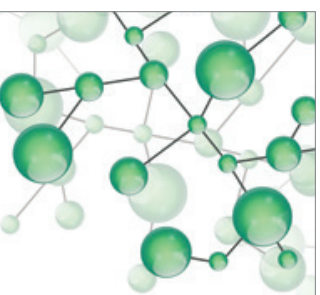

International Journal of

Inorganic Chemistry

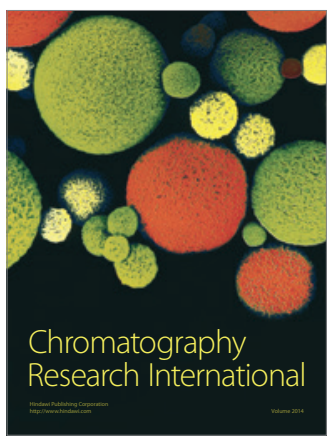

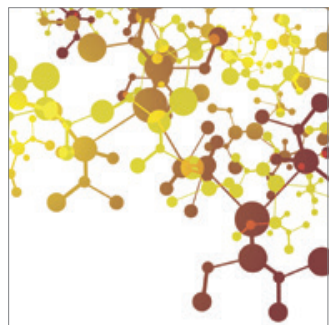

Applied Chemistry
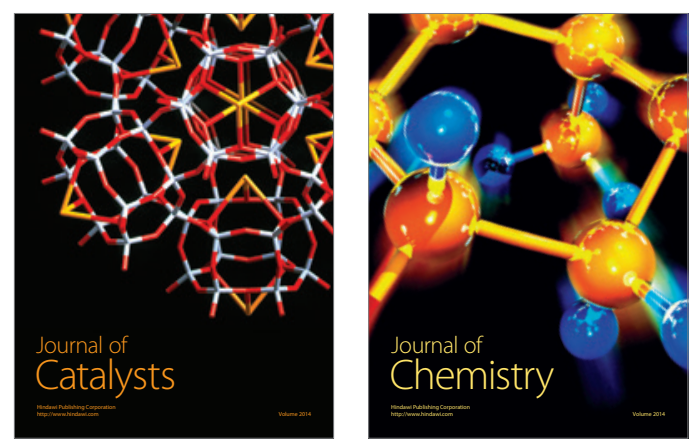
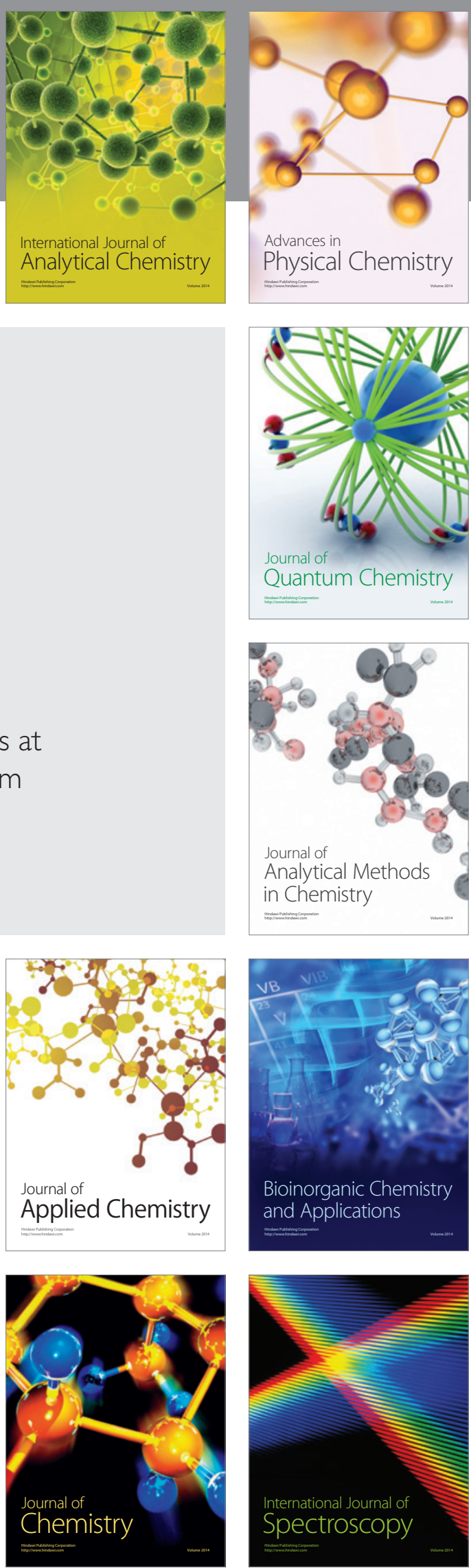